\title{
PERCEPCÕES DE CONSUMIDORES ACERCA DOS INFORMATIVOS NUTRICIONAIS: POTENCIALIDADES E FRAGILIDADES
}

\section{Amanda Vargas Spat ${ }^{1}$; Natalia Brugalli Ribeiro ${ }^{2}$; Fernanda da Rosa Cardoso ${ }^{3}$; Patricia Arruda Scheffer ${ }^{4}$; Juliana Silveira Colomé5; Ana Lúcia de Freitas Saccol ${ }^{6}$}

\section{RESUMO}

O consumidor está cada vez mais exigente e buscando informações nos alimentos. Neste contexto, o objetivo deste estudo foi apresentar as potencialidades e as fragilidades identificadas por consumidores em relação aos informativos nutricionais. Além disto, avaliou-se o nível de entendimento e compreensão quanto aos modelos expostos em sanduíches. Trata-se de um estudo de abordagem qualitativa, cuja técnica de coleta de dados foi o grupo focal. O grupo focal foi realizado em dezembro de 2020, com seis pessoas no Laboratório de técnica dietética da universidade. Os dados, após serem transcritos, foram submetidos à análise de conteúdo. Os resultados demonstraram que o informativo com maior aceitabilidade foi o de Alerta. Conclui-se que o informativo de maior aceitabilidade teve como justificativa de preferência a objetividade na exibição do alerta de excesso.

Palavras-chave: Rotulagem Nutricional; Qualidade de Alimentos; Nutrição.

Eixo Temático: Atenção Integral e Promoção à Saúde - AIPS

\section{INTRODUÇÃO}

$\mathrm{Na}$ área de segurança alimentar, a rotulagem consiste em uma ferramenta fundamental de informação e orientação ao consumidor sobre a qualidade e quantidade dos componentes nutricionais dos alimentos, permitindo que o cliente faça

\footnotetext{
1 Bolsista Probic/UFN - Universidade Franciscana, amanda.spat@ufn.edu.br.

2 Acadêmica do Curso de Nutrição, Bolsista PROBITI/FAPERGS - Universidade Franciscana, n.brugalli@ufn.edu.br

3 Nutricionista. Universidade Franciscana, carfernanda.97@gmail.com

4 Nutricionista. Mestranda em Ciências da Saúde e da Vida. Grupo de Pesquisa em Segurança Alimentar e Nutricional (GESAN/CNPq)- Universidade Franciscana, patricia.scheffer@ufn.edu.br 5 Docente no Curso de Enfermagem e Mestrado em Ciências da Saúde e da Vida, Universidade Franciscana - UFN. Email: juliana@ufn.edu.br

6 Professora Orientadora, Curso de Nutrição e Mestrado em Ciências da Saúde e da Vida, UFN, Grupo de Pesquisa em Segurança Alimentar e Nutricional (GESAN/CNPq), alsaccol@ufn.edu.br
} 
escolhas alimentares condizentes com seu estilo e condições de vida. Observa-se que a rotulagem possui impacto na mídia e propaganda, e ainda presta o maior número de informações acerca de um produto, influenciando na hora da escolha do consumidor (JARDIM et al., 2016).

A rotulagem nutricional frontal (RNF) é recomendada internacionalmente como ferramenta para auxiliar o consumidor na interpretação das declarações quantitativas de nutrientes dos alimentos, que podem ser de difícil entendimento por serem apresentadas em letras miúdas no verso das embalagens. Grande parte da população brasileira tem dificuldade na interpretação de informações disponibilizadas nos rótulos. Sem compreender o conteúdo do alimento, confusões quanto à saudabilidade podem acontecer, levando o consumidor ao erro (BANDEIRA et al., 2021).

Em outubro de 2020, a Agência Nacional de Vigilância Sanitária (ANVISA) aprovou a nova norma de rotulagem nutricional para alimentos embalados, a Resolução da Diretoria Colegiada - RDC n. 429/2020, que dispões sobre a rotulagem nutricional dos alimentos embalados e se aplica àqueles embalados na ausência dos consumidores, incluindo as bebidas, os ingredientes, os aditivos alimentares e os coadjuvantes de tecnologia, inclusive aqueles destinados exclusivamente ao processamento industrial ou aos serviços de alimentação (BRASIL, 2020).

A Instrução Normativa (IN) - n. $975 / 2020$, traz como inovação a rotulagem nutricional frontal, obrigatória nos rótulos dos alimentos embalados na ausência do consumidor cujas quantidades de açúcares adicionados, gorduras saturadas ou sódio sejam iguais ou superiores aos limites definidos, não sendo obrigatória para aqueles com área de painel principal inferior a $35 \mathrm{~cm}^{2}$; alimentos embalados nos pontos de venda ou a pedido do consumidor; e para alimentos embalados preparados ou comercializados no próprio estabelecimento (BRASIL, 2020).

A formação de grupos focais é definida como uma técnica de pesquisa que coleta dados privilegiando as interações grupais através de debate sobre um tópico sugerido pelo pesquisador. São um recurso para auxiliar na compreensão do processo de construção das percepções, atitudes e representações sociais de determinados grupos sociais. Os grupos focais são utilizados quando o foco de análise é a interação 
entre os participantes de um grupo de discussão (MARCONDES; TEIXEIRA; OLIVEIRA, 2010).

Para que ocorra uma contribuição do grupo focal de maneira eficaz sobre assuntos relativos aos informativos nutricionais, é importante saber o que os indivíduos enfrentam e buscam na hora de escolher alimentos expostos em balcões ou buffets. Assim pode-se identificar o que os participantes pretendem encontrar no debate em grupo e permitir que as sugestões deles sejam inseridas no desenvolvimento e melhora dos informativos (POHLMEIER et al., 2012).

Neste contexto, o objetivo deste estudo foi apresentar os resultados parciais obtidos em um grupo focal que avaliou a influência de informativos nutricionais na escolha dos alimentos, o modelo proposto preferido pelos participantes, bem como as justificativas. Além disto, avaliou-se o nível de entendimento e compreensão quanto aos modelos expostos em sanduíches.

\section{METODOLOGIA}

O presente estudo faz parte do Grupo de Pesquisa em Segurança Alimentar e Nutricional (GESAN), onde foram elaboradas previamente algumas propostas de informativos nutricionais para serviços de alimentação. Na figura 1, apresentam-se os modelos elaborados pelo GESAN.

Figura 1 - Modelos de informativos nutricionais para serviços de alimentação, modelo convencional, modelo do semáforo e modelo alerta, Santa Maria - RS, 2020.
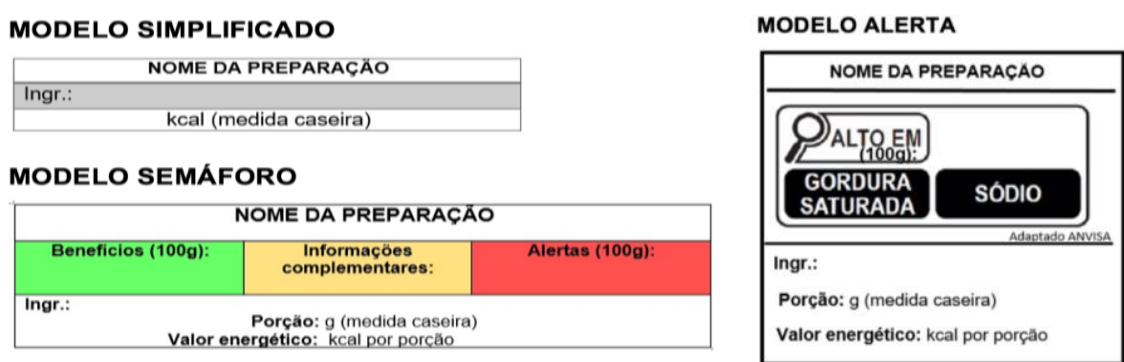

O presente trabalho é um estudo descritivo, qualitativo, onde foi utilizada a técnica de grupos focais, a fim de analisar as percepções e as preferências de adultos jovens por diferentes formatos de informações nutricionais. O corpus transcrito foi submetido à Análise de Conteúdo sistemática dedutiva (BARDIN, 2010) 
Segundo Godoy (1995), quando o objeto de estudo é pouco conhecido e utiliza-se a abordagem exploratória, a pesquisa qualitativa é a mais indicada. O estudo qualitativo destina-se a obter dados através de contato direto e interativo do pesquisador com o objeto a ser estudado (NEVES, 1996).

Em relação à execução do grupo focal, foi realizada a seleção do local de estudo, sendo pré-estabelecida a aplicação na Universidade Franciscana por questão de conveniência e de viabilidade. A população-alvo do estudo foram indivíduos adultos que se alimentam fora de casa. O recrutamento foi realizado por meio de convites determinados a pessoas de diferentes etnias, sendo um grupo heterogêneos quanto ao sexo, idade, e crenças contando com a presença de 8 participantes. Vale ressaltar que os participantes responderam ao questionário sociodemográfico no momento do envio do convite, para garantir que os integrantes fossem distintos em suas características.

O grupo focal foi realizado em dezembro de 2020 no laboratório de técnica e dietética previamente agendada na Universidade Franciscana, respeitando todos os protocolos de segurança higiênico sanitária, referentes ao COVID-19. Uma única moderadora treinada conduziu o grupo com o auxílio de duas observadoras para fazer anotações. A sessão foi gravada com auxílio de aplicativo instalado em dispositivo móvel.

Os voluntários foram informados sobre os objetivos da pesquisa, em relação ao conteúdo sigiloso das informações e sobre o funcionamento do grupo, ressaltando que cada participante teve seu momento de falar e que não houve respostas certas ou erradas. Os participantes foram instruídos a dar respostas honestas sobre o que pensavam a respeito do tema, visto que o estudo objetivou explorar percepções e não avaliar as respostas.

A ordem de apresentação dos modelos foi de tal forma que os mais conhecidos e simples foram os primeiros a serem abordados, facilitando o entendimento da dinâmica e a interação dos membros do grupo. Por esta razão, o primeiro sanduíche exposto foi o Hambúrguer, na sequência o Sanduíche de Frango e logo depois o Sanduíche de Presunto e Queijo, todos expostos em uma mesa branca, dentro do laboratório da Universidade Franciscana, conforme figura 2. 
Depois da apresentação e da discussão em profundidade dos três diferentes modelos de informações nutricionais, os participantes foram convidados a tecer comentários ou sugestões a respeito dos modelos apresentados.

Figura 2- Sanduíches e Informativos Nutricionais expostos durante o grupo focal, Santa Maria - RS, 2020.

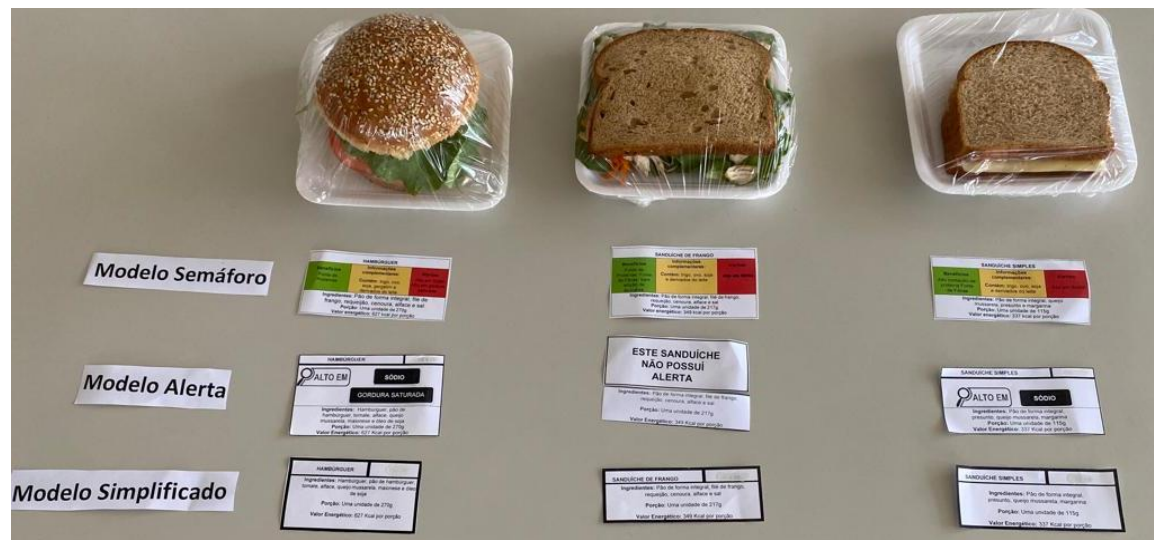

Para uma melhor organização, um roteiro com perguntas norteadoras foram realizadas pelas mediadoras. O roteiro era organizado com quatro perguntas, sendo elas: "O que você leva em consideração para escolher um desses sanduíches para consumir? Porquê?"; "Qual destes modelos de informativo você prefere? Porque?"; "Qual destes modelos de informativo é de mais fácil entendimento? Porquê?"; "Qual destes modelos de informativo influencia na sua escolha? Porquê?".

A pesquisa possui aprovação no Comitê de Ética em Pesquisa da Universidade Franciscana (UFN), por meio do parecer 1.877.129. Os participantes do grupo focal assinaram um Termo de Consentimento Livre e Esclarecido (TCLE), uma via ficando com o participante e outra com as pesquisadoras.

\section{RESULTADOS E DISCUSSÕES}

\subsection{Características dos participantes}

Participaram do grupo focal seis pessoas (tabela 1), de diferentes idades, profissões e escolaridades. Mais da metade dos participantes eram do sexo feminino 


\section{QUFN}

$(n=6)$. Vale destacar, que cinco participantes possuem alguma condição de saúde, sendo relatado: hipertensão, síndrome do intestino irritável, intolerância à lactose, mas todos assinalaram estar em busca de uma alimentação saudável.

Tabela 1 - Características dos participantes $(n=6)$ do grupo focal sobre informativos nutricionais em serviços de alimentação, Santa Maria, RS, 2020.

$\begin{array}{llll}\text { Participantes } & \text { Sexo } & \text { Idade } & \text { Profissão }\end{array}$

Feminino $\quad 46$ anos

Funcionária da Universidade

Franciscana

2

Feminino

51 anos

Funcionária da Universidade

Franciscana

3

Feminino

52 anos

Funcionária de restaurante

4

Feminino

22 anos

Estudante de Fisioterapia

5

Masculino 29 anos

Biólogo

6

Feminino

41 anos

Farmacêutica

7

Masculino

30 anos

Estudante de Enfermagem

8

Feminino

32 anos

Gerente de restaurante

Percebe-se que cada vez mais o público feminino está ativo em pesquisas voltadas para a saúde. Diversos estudos apontam as mulheres como o maior número 
EDUCAÇÃO, SAÚDE

ETECNOLLOGIA

26 A 28 DE OUTUBRO DE 2021

de participantes em seus estudos (LASSEN et al., 2014; PEREZ et al., 2017). Vários fatores podem estar associados a esta alta adesão, uma delas é que as mulheres buscam cada vez mais por qualidade de vida, pois preocupam-se mais com sua saúde.

\subsection{Potencialidades e fragilidades dos Informativos Nutricionais}

Tendo em vista que a investigação na análise qualitativa busca respostas aos objetivos traçados em uma pesquisa, conhecer o que o público-alvo o qual é destinado o produto/ação necessita, torna-se fundamental para o delineamento dos próximos passos a serem seguidos. Por esta razão, entender as potencialidades e fragilidades de um instrumento transforma-se em algo elementar para futuros investimentos e disponibilização para toda comunidade.

Para os integrantes do grupo focal, o modelo de Informativo Nutricional Semáforo possui diversos benefícios, além de ser o mais completo, é o que mais chama atenção, devido à presença de cores, isto pode ser observado, conforme as transcrições abaixo. Segundo Kim et al., (2018) as cores são um dos fatores que mais chamam a atenção visual das pessoas.

\footnotetext{
"Eu acho ele mais detalhado, ele explica mais os materiais utilizados, os ingredientes. Eu acho que para quem procura uma alimentação saudável é o mais indicado ao meu ver" (participante 1)

"o mais completo é o método semáforo e o que me chama atenção são as cores, o que acho muito importante, é uma questão mais didática mais fácil de você visualizar talvez se você não quer ler tudo você vai direto para as cores e aí você já vê o que você qual risco está correndo" (participante 6)
}

Apesar que para alguns, o Semáforo ser o mais completo e o mais apropriados para aqueles que buscam por mais informações, o fato de aplicá-lo em um serviço de buffet talvez não seja o mais adequado, isto pode ser constatado pelas seguintes falas:

"Eu por exemplo não vou parar pra ler na cantina com fila pra ler o semáforo, por ter vários produtos" (participante 5)

"(...) eu acho que as pessoas estão com pouco tempo para chegar e ler" (participante 8) 
Segundo Pohlmeier et al. (2012), uma desvantagem potencial do método do semáforo é o aspecto social de ter alimentos rotulados com cores que representam seu grau de salubridade. Essa observação sugere que mesmo interessados em informações, a rotina apressada dos consumidores e os curtos períodos para realização das refeições pode limitar a percepção das pessoas sobre a real importância das informações nutricionais contidas no informativo.

Quando apresentados ao segundo Informativo Nutricional, denominado Alerta, os participantes acreditam que, mesmo com a ausência das cores, o informativo acaba sendo mais objetivo e claro aos olhos dos consumidores.

"O lado positivo do alerta é que é mega objetivo... alto em sódio ... alto em..." (participante 4)

"Eu achei esse modelo mais objetivo, ele vai direto, se tem risco ou não" (participante 6)

A presença da cor preta pode ser uma limitação para a aceitabilidade deste informativo pelos consumidores. A fala de uma gestora de um restaurante comercial (participante 8), ressalta que o informativo enfatiza apenas o que é "ruim" para a saúde e não mostra os benefícios daquela preparação, por isso poderia não ser uma boa escolha, pela visão de um empreendedor.

"( ...) no semáforo tu vê que tu tem o bom, o mais ou menos e o ruim...entao nao ta identificando...já o alerta fala o que é ruim. Também se eu to comendo uma coisa saudável, parece que não tá esclarecendo se estou consumindo é saudável mesmo"

(participante 8)

"Talvez o alerta não precisasse ser preto, a cor preta é um pouco pesada....como ela disse, parece que você está servindo coisas ruins e não é de todo ruim é só um alerta...poderia ser um amarelo"

(participante 1)

“(...) eu acredito que no restaurante dava pra mudar e colocar uma cor mais suave, porque dai não tem tanta informação é o alimento e a etiqueta"

(participante 6)

O fato de não possuir muitas informações ao consumidor, o Informativo Nutricional Simplificado mostrou-se limitante no momento da escolha de uma refeição ou lanche, segundo relato dos participantes.

"Eu acho que não influencia muito na escolha, primeiro porque pra quem tá escolhendo um lanche se torna mais difícil, porque pra ele não tá dizendo se é saudável....eu acho que pra ele é um pouco mais difícil" (participante 8)

"Pelo o que eu vejo neste modelo, nada nele se destaca, diferente dos outros" 
Nos serviços de alimentação, normalmente os alimentos expostos em buffet e balcões expositores apresentam no máximo a designação do produto e o preço. Atualmente não é exigido nenhum tipo de informação nutricional para esses alimentos. Entretanto é importante ressaltar que um alto percentual da população apresenta restrições alimentares e quadros alérgicos que envolvem alimentos ou componentes alimentares como fator causal (NASCIMENTO; SOUZA, 2018). Tendo em vista essa situação é relevante ter um informativo que agregue ao consumidor, como o modelo Simplificado possui poucas informações e não apresenta muitos detalhes, acaba não atraindo a atenção do consumidor

Nos produtos industrializados, o rótulo tem a função de orientar o público sobre os componentes e propriedades dos alimentos, fazendo com que o consumidor esteja ciente quanto ao produto que está comprando e opte por realizar boas escolhas alimentares. Porém isso não acontece em alimentos ofertados em serviços de alimentação, o que pode dificultar as escolhas corretas. Neste cenário, onde muitos consumidores possuem doenças crônicas ou alergias alimentares que impossibilitam a ingestão de algum alimento específico, é de suma importância que as informações nutricionais sejam esclarecedoras e visíveis, proporcionando escolhas mais conscientes e saudáveis (CAVADA et al., 2012).

\section{CONCLUSÃO}

Concluiu-se que os modelos de informativos nutricionais de Alerta e Semáforo foram respectivamente os que obtiveram melhor aceitabilidade e compreensão observadas pelos participantes do grupo focal, tendo em vista a qualidade e a quantidade das informações dispostas, bem como a praticidade de exposição das mesmas. Sendo o modelo Alerta o informativo com maior aceitabilidade pelo grupo focal, que se norteou através de perguntas sobre influência na escolha, a mais influente relacionada à objetividade na percepção dos alertas sobre os excessos. 


\section{QUFN}

\section{AGRADECIMENTOS}

Agradecemos à Universidade Franciscana pela bolsa Probic; e a Fundação de Amparo à Pesquisa do Estado do Rio Grande do Sul (FAPERGS) pelo apoio financeiro neste projeto.

\section{REFERÊNCIAS}

BANDEIRA, L. M. et al. Desempenho e percepção sobre modelos de rotulagem nutricional frontal no Brasil. Revista de Saúde Pública, v. 55, n. 19, 2021.

BARDIN, L. Análise de conteúdo. Lisboa: Ed. 70, p. 281, 2010.

BRASIL, Ministério da Saúde - MS Agência Nacional de Vigilância Sanitária ANVISA. RESOLUÇÃO DA DIRETORIA COLEGIADA - RDC № 429, DE 8 DE OUTUBRO DE 2020. Disponível em:

http://antigo.anvisa.gov.br/documents/10181/3882585/RDC 4292020 .pdf/9dc15f3 a-db4c-4d3f-90d8-ef4b80537380

BRASIL, Ministério da Saúde - MS Agência Nacional de Vigilância Sanitária ANVISA. INSTRUÇÃO NORMATIVA - IN N 75, DE 8 DE OUTUBRO DE 2020. Disponível em: http://antigo.anvisa.gov.br/documents/10181/3882585/IN+75 2020 .pdf/7d74fe2d$\underline{\text { e187-4136-9fa2-36a8dcfc0f8f }}$

CAVADA, G. S. et al. Rotulagem nutricional: você sabe o que está comendo?. Braz. J. Food Technol, p. 84-88, 2012.

JARDIM, F. B. B. et al. Rotulagem de alimentos: avaliação e orientação às indústrias e aos consumidores quanto aos aspectos legais e informativos dos rótulos. Boletim Técnico IFTM, v. 2, n. 1, p. 26-29, 2016.

LASSEN, A. D. et al. Effectiveness of offering healthy labelled meals in improving the nutritional quality of lunch meals eaten in a worksite canteen. Appetite, v. 75, p. 128-134, 1 abr. 2014.

$\mathrm{KIM}$, E. et al.Optimization of menu-labeling formats to drive healthy dining: An eye tracking study.International Journal of Hospitality Management, v.70, p.37-38, 2018.

MARCONDES, M. I.; TEIXEIRA, E.; OLIVEIRA, I. A. Metodologias e Técnicas de Pesquisa em Educação. Belém: EDUEPA, 2010.

NASCIMENTO, J. M.; SOUZA, A. O. Avaliação das informações nutricionais e ingredientes declarados em rótulos de pães integrais comercializados em supermercados de Belém, Pará. Demetra, v. 13, n. 4, p. 793-817, 2018. 


\section{QUFN}

PÉREZ, C. et al. Efeito da rotulagem de calorias na seleção do menu: um estudo preliminar em Santiago, Chile. Rev Chil Nutr, v. 44, 2017.

POHLMEIER, A. et al. Using Focus Groups to Develop a Nutrition Labeling Program within University Food Service. Family \& Consumer Sciences Research Journal, v. 40, n. 4, p. 431-443, jun. 2012. 